\title{
Study on Precipitation Evolution Characteristics in Tongzhou District of Beijing in Recent 65 Years
}

\author{
Xue ZHANG ${ }^{\text {a,b,c }}$, Juan ZHANG ${ }^{\text {a,c,1 }}$, Xiujie ZHANG ${ }^{\text {d }}$, Moyuan YANG ${ }^{\text {a,c }}$, Xingyao \\ PAN $^{\mathrm{a}, \mathrm{c}}$, Chen LIU $^{\mathrm{d}}$ and Shengli YANG ${ }^{\mathrm{a}, \mathrm{c}}$ \\ ${ }^{a}$ Beijing Water Science and Technology Institute, Beijing, China \\ ${ }^{\mathrm{b}}$ College of Resources, Environment and Tourism, Capital Normal University, Beijing, \\ China \\ ${ }^{\mathrm{c}}$ Beijing Engineering Technique Research Center for Exploration and Utilization of \\ Non-Conventional Water Resources and Water Use Efficiency, Beijing, China \\ ${ }^{\mathrm{d}}$ Beijing Tongzhou District Water Authorit, Beijing, China
}

\begin{abstract}
Based on the 65a (1956-2020) precipitation series data of 11 rainfall stations and 5 surrounding rainfall stations in Tongzhou District, Beijing, the evolution characteristics of precipitation in Tongzhou District on spatial, interannual and intra annual scales are comprehensively analyzed using cumulative anomaly method, 5a moving average method and spectral analysis method, and the future change trend is predicted using ARIMA model. The results show that: 1) the annual average precipitation in Tongzhou District is higher in the middle and northwest and lower in the southwest, and the precipitation between June to August, accounts for more than $70 \%$ of the annual precipitation; 2) In general, the precipitation shows a fluctuating downward trend at the rate of $-2.42 \mathrm{~mm} \mathrm{a}^{-1}$, in which the precipitation in summer decreases at the rate of $-2.68 \mathrm{~mm} \mathrm{a}^{-1}$, while the precipitation in spring and autumn increases at the rates of $0.35 \mathrm{~mm} \mathrm{a}^{-1}$ and 0.26 $\mathrm{mm} \mathrm{a}^{-1}$ respectively; 3 ) The abrupt change of precipitation occurred in 1959 and 2000 , which were $990.2 \mathrm{~mm}$ and $239.4 \mathrm{~mm}$ respectively; 4) There are $3 \sim 8 \mathrm{a}$ and 14 16a oscillation periods on the inter annual scale of precipitation, the prediction results of ARIMA model show that the precipitation will increase about $40 \mathrm{~mm}$ in the next five years.
\end{abstract}

Keywords. Tongzhou, precipitation, cumulative anomaly method, moving average method, spectral analysis, time series model

\section{Introduction}

Precipitation is the basic element of hydrological cycle, and human activities have significantly changed the evolution law of water cycle. Studying the characteristics of precipitation can deepen the understanding of water cycle in urban construction area [1]. In recent years, many studies have been carried out on the temporal and spatial evolution law of precipitation at watershed and regional scales: Liu XP [2], Kong F [3], Duan YW and others [4] studied the concentration degree and temporal and spatial

\footnotetext{
1 Juan Zhang, Corresponding author, The main research direction is the utilization and evaluation of urban water resources, Hebei, China; E-mail: zhangjuan0419@163.com.
} 
pattern of precipitation in China; Zou XJ [5] and Lu J [6] carried out multi-scale analysis of precipitation in the Pearl River Delta and Beijing Tianjin Hebei region based on daily precipitation data of a long series of meteorological stations; Liu L [7] and others analyzed the interdecadal variation characteristics of precipitation in Wuhu area in recent 140 years. Li M et al. [8] analyzed the interannual variation time series of precipitation in Beijing in recent 300 years, and revealed the multi time scale periodic variation law of precipitation in this area; Li B et al. [9] analyzed the extreme rainfall threshold and temporal and spatial evolution law by using percentile threshold method, moving average method and other methods based on the occurrence frequency and cumulative value of four grades of small, medium, heavy and heavy rainfall in Tongzhou District, Beijing. Xia LB [10] predicted the precipitation trend of Baotou City for 276 months from 1951 to 1973 by spectral analysis method; Chen P et al. [10] analyzed and predicted the main climatic factors such as precipitation, temperature and air humidity in Yunnan Province by establishing ARIMA model.

At present, due to the shortage of high-density and long-series rainfall data, the analysis of regional small-scale precipitation mostly focuses on the study and judgment of extreme rainfall and flood risk $[12,13]$, and the analysis of spatial distribution, interannual variation and seasonal characteristics of small-scale regional precipitation is not deep enough. Taking Tongzhou District of Beijing as an example, based on the complete long series monthly precipitation data of 16 rainfall stations for 65 years, this paper comprehensively uses the cumulative anomaly method, 5A moving average method and spectral analysis method to carry out multi-scale analysis and Research on the spatial, interannual and seasonal changes of rainfall in the study area. At the same time, based on the time series model, this paper explores the periodic law of precipitation and forecasts the future precipitation changes, which lays a foundation for studying the long-term evolution characteristics and seasonal variation law of precipitation in typical plains of Beijing, and provides a scientific basis for the fine management of regional water resources.

\section{Overview of the Study Area}

Tongzhou District is located at the intersection of Yongding River and Chaobai River alluvial proluvial plain. It belongs to the middle and lower reaches of alluvial proluvial plain. It is a fan-shaped plain composed of alluvial proluvial facies sediments. It is $36.5 \mathrm{~km}$ wide from east to west and $48 \mathrm{~km}$ long from north to south, with a total area of $906 \mathrm{~km}^{2}$. The region has a typical warm temperate semi humid and semi-arid continental monsoon climate with four distinct seasons. It is dry and rainy in spring, hot and rainy in summer, high and crisp in autumn and dry and cold in winter.

The regional multi-year average temperature $(1956 \sim 2020)$ is $12.21^{\circ} \mathrm{C}$, and the monthly average temperature in July is the highest, $26.51{ }^{\circ} \mathrm{C}$; The lowest monthly average temperature in January is $-3.98{ }^{\circ} \mathrm{C}$, and the average temperature difference is $30.49{ }^{\circ} \mathrm{C}$. The annual average precipitation is about $532.1 \mathrm{~mm}$, and more than $80 \%$ of the annual precipitation is concentrated in the flood season from June to September. The annual average water surface evaporation is $1215.0 \mathrm{~mm}$, with the maximum evaporation in May and the minimum evaporation in January. The monthly average changes of precipitation, evaporation and temperature in the study area are shown in 0 . 


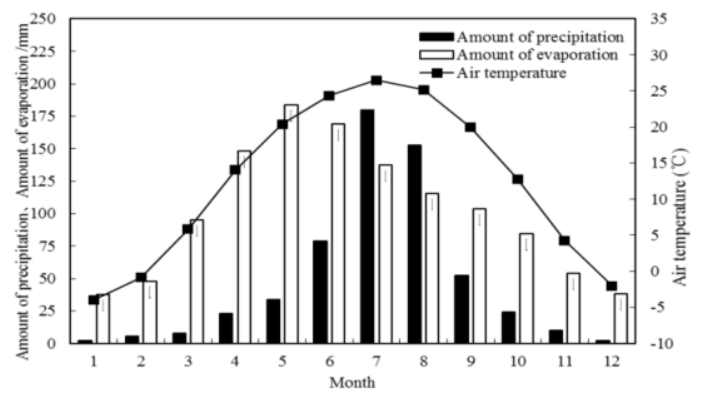

Figure 1. Comparison of precipitation-evaporation-temperature in Tongzhou District.

\section{Data and Research Methods}

\subsection{Data}

This paper selects the monthly precipitation data of 16 rainfall stations in Tongzhou District and four surrounding areas from 1956 to 2020 (65a). Based on the statistics of measured data, the rainfall stations with discontinuous data, missing measurement in individual years or failing to meet the 65 years synchronous series standards are extended or interpolated by means of direct transfer or correlation analysis of adjacent stations, and the distribution of specific rainfall stations is showed in figure 2 .

\subsection{Research Methods}

\subsubsection{Spatial Interpolation Analysis Method}

In order to quantify the difference of precipitation in the region, this paper combines spatial analysis technology to mesh the study area [13], and the grid scale is $100 \mathrm{~m} \times$ $100 \mathrm{~m}$. Considering the terrain, landform, climate and distribution trend of large precipitation over the years, the interpolation method is used to quantify the annual precipitation of each grid in the whole region, and the grid method is used to calculate the annual surface precipitation of Tongzhou.

\subsubsection{Precipitation Trend Analysis Method}

There are many analysis methods for the change trend of hydrological elements. In this paper, the moving average method [15] and cumulative anomaly method [16] are comprehensively used to analyze the trend and mutation of historical precipitation series in the study area, and the spectral analysis method [16] and ARIMA model [18] are used to analyze the precipitation cycle and predict the future precipitation trend.

Based on the simple average method, the moving average method calculates the average value by increasing and decreasing the old and new data phase by phase, so as to eliminate the accidental change factors and obtain a new sequence. The new sequence becomes smoother and can clearly show the trend change. The precipitation tendency rate is greater than 0 , indicating that the precipitation tends to increase on the 
whole, on the contrary, it decreases [19]. This method can well eliminate the unstable fluctuation of the original annual precipitation data and show the stability of the change of annual precipitation series [20]. The calculation formula is as follows:

$$
y_{t}=\frac{1}{2 k+1} \sum_{i=-k}^{k} x_{t+i}
$$

Where: $y_{t}$ is the moving average series value; $i$ is the number of sequence values after sliding; $\mathrm{k}$ is the sliding length, generally, the value of $\mathrm{k}$ is 2 , which is called $5 \mathrm{~A}$ moving average.

The cumulative anomaly method judges the long-term evolution trend and continuous change of precipitation according to the fluctuation of the curve, and determines the catastrophe year [21] [22]. The calculation formula is as follows:

$$
\begin{aligned}
& x=\sum_{i=1}^{t}\left(x_{i}-\bar{x}\right) \\
& \bar{x}=\frac{1}{n} \sum_{i=1}^{n} x_{i}
\end{aligned}
$$

Where: $\mathrm{t}=1,2,3 \ldots \mathrm{n}$, xi represents the precipitation in year $\mathrm{i}, \bar{X}$ represents the annual average precipitation.

Spectral analysis is widely used in meteorology. The basic principle is Fourier analysis. Spectral density map is a simple and effective method to study the periodicity of hydrological time series [23]. Analyze the periodicity of the study area according to frequency fluctuation.

ARIMA model predicts future precipitation changes. ARIMA model is also called integrated moving average autoregressive model. The basic idea of ARIMA modeling is to perform differential processing on the studied non-stationary time series data to turn it into a stationary time series, and then use the actual value of time series to establish a model for prediction [24].

\section{Result Analysis}

\subsection{Analysis of Spatial Distribution Characteristics of Precipitation}

According to the precipitation data of 16 rainfall stations in Tongzhou District from 1956 to 2020, the GIS spatial information database of regional precipitation sequence is established, and the contour map of multi-year average precipitation in Tongzhou District from 1956 to 2020, 1980 to 2020 and 2001 to 2020 is drawn, as shown in figure 3. From the analysis of precipitation isoline maps of three periods, the distribution of high value areas of precipitation and the trend of isoline in Tongzhou 
District are basically the same, and the spatial distribution of multi-year average precipitation is higher in the middle and northwest and lower in the southwest.

Taking the isoline of average precipitation from 1956 to 2020 as an example, the precipitation at different stations is unevenly distributed [25]. The precipitation in some areas of Tongxian county and Yulinzhuang and Mizidian stations in the East is concentrated above $550 \mathrm{~mm}$, of which Tongxian station is the precipitation center, and the precipitation is more than 560mm; The precipitation of Majuqiao, Niubaotun, Yongledian and Chaichangtun stations in the southwest is mostly less than $530 \mathrm{~mm}$, and the farther to the southwest, the smaller the rainfall.

Since 1999, Beijing has experienced the most serious drought period since the founding of new China. From the precipitation isolines of the two periods from 2001 to 2020 and 1956 to 2020, the values of different regions have decreased, such as Songzhuang, Gantang and Xiji. The isoline values of 2001 to 2020 are about $60 \mathrm{~mm}$ lower than those of 1956 to 2020 , but the trend of the isoline is basically the same.

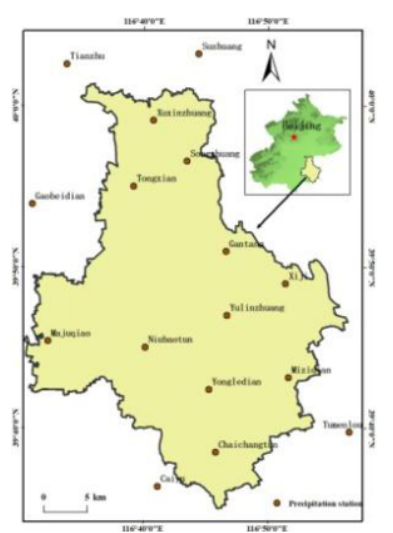

Figure 2. Distribution of rainfall stations in Tongzhou District.

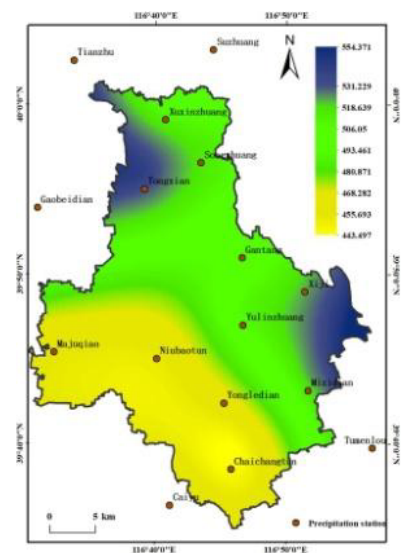

(b)

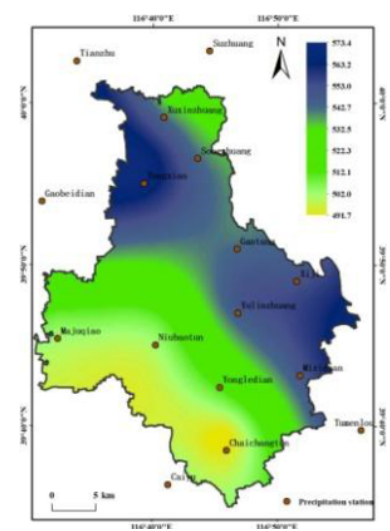

(a) 


\subsection{Analysis of Interannual Variation of Precipitation}

The 65 years annual precipitation hydrograph of Tongzhou District from 1956 to 2020 is shown in 0 . The results show that the annual average precipitation of Tongzhou District is $532.1 \mathrm{~mm}$. The precipitation has been abundant and dry for many years, and the longest continuous wet year is 4 years, such as $1976 \sim 1979$; The longest continuous dry year is 13 years, such as $1999 \sim 2011$; In the long run, since the 1980 s, the low water section has occurred more frequently and lasted longer.

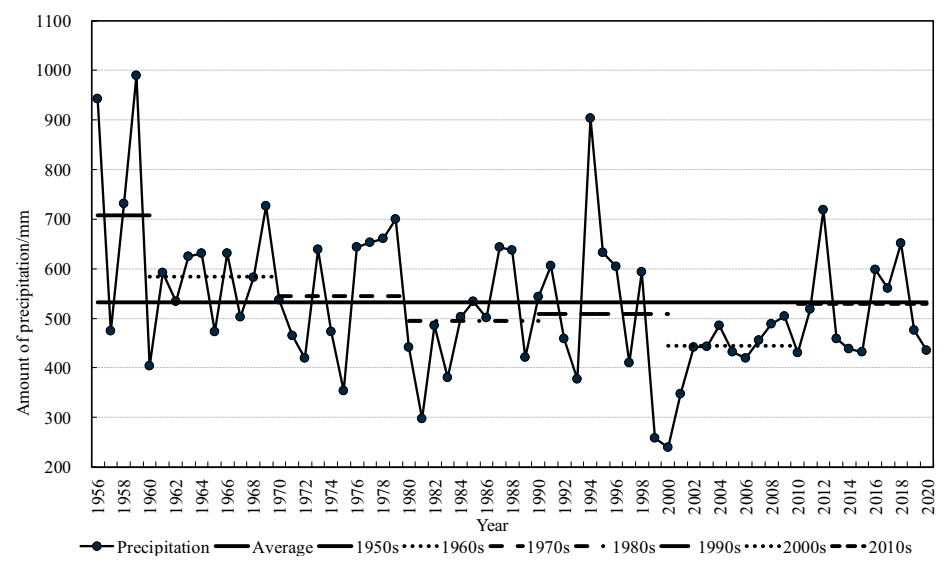

Figure 4. Tongzhou precipitation hydrograph over the years.

Generally speaking, the average annual precipitation in the 1950s was higher than the multi-year average, reaching $708.4 \mathrm{~mm}$, with abundant precipitation; It was slightly higher than the multi-year average in the 1960s and 1970s, and slightly lower than the multi-year average in the 1980s and 1990s; The average precipitation from 2001 to 2010 is significantly lower than the multi-year average, only $444.8 \mathrm{~mm}$; Since 2010 , the average precipitation has been in line with the multi-year average. By comparing the precipitation over the years in Tongzhou District with the precipitation estimated by curve fitting method in wet years, normal years, dry years and extremely dry years, it can be seen that the wet years occur 10 times, and the ratio is only $15.4 \%$; It occurs 20 times in a normal year, accounting for $30.8 \%$; It occurs 23 times in dry years, accounting for $35.4 \%$, as shown in table 1 .

Table 1. Precipitation grade of high, flat and dry season in Tongzhou District from 1956 to 2020.

\begin{tabular}{llllll}
\hline Typical year & Wet year & Normal year & Dry year & Dryer year & Dryest year \\
\hline Guarantee rate & 0.2 & 0.5 & 0.75 & 0.85 & 0.95 \\
Precipitation $(\mathrm{mm})$ & $\geq 649.8$ & $649.8 \sim 514.2$ & $514.2 \sim 424.8$ & $424.8 \sim 320.5$ & $\leq 320.5$ \\
Number of years & 10 & 20 & 23 & 9 & 3 \\
Percentage (\%) & 15.4 & 30.8 & 35.4 & 13.8 & 4.6 \\
\hline
\end{tabular}

In order to more intuitively reflect the long-term variation trend and sudden change of rainfall in the study area, the moving average method and cumulative anomaly method are used to analyze the rainfall sequence respectively. The $5 \mathrm{~A}$ moving average 
curve and cumulative anomaly curve of precipitation are shown in 0 . From the $5 \mathrm{~A}$ moving average curve, it can be seen that the annual precipitation presents a strong fluctuation, the precipitation in Tongzhou District presents a fluctuation trend of "decrease increase decrease increase decrease increase decrease" as a whole, and the linear trend line reflects that the annual precipitation in the study area shows a downward trend as a whole. The results of cumulative anomaly curve analysis show that the maximum mutation years occurred in 1959 and 2000, of which the maximum annual precipitation in 1959 was $990.2 \mathrm{~mm}$ and the minimum annual precipitation in 2000 was $239.4 \mathrm{~mm}$, with a ratio of 4.14 .

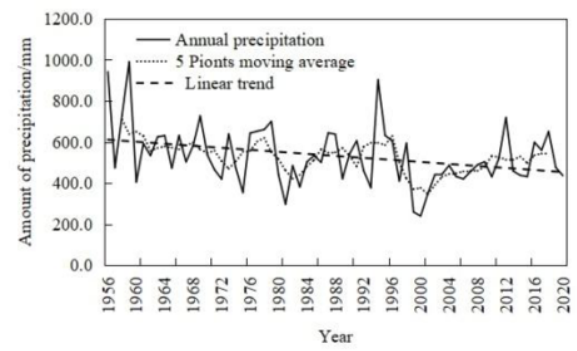

(a)

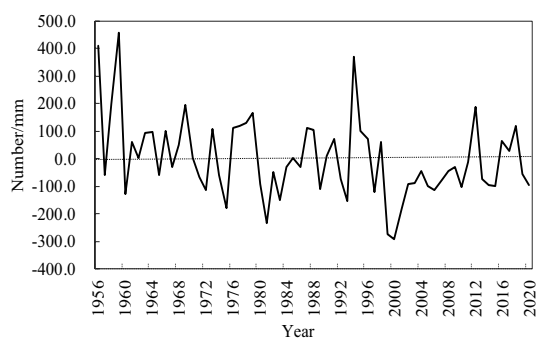

(b)

Figure 5. (a)Variation of annual precipitation; (b) Cumulative anomaly map.

\subsection{Analysis of Seasonal Variation of Precipitation}

The annual distribution proportion of multi-year average precipitation in Tongzhou District shows an obvious seasonal precipitation distribution. The seasonal division standard is March may in spring, June August in summer, September November in autumn and December February in winter. According to the annual distribution analysis results of multi-year average precipitation of typical stations in the study area, the precipitation gradually increases from April every year. The precipitation is mainly concentrated in June to August every year, accounting for about $72.2 \%$ of the annual precipitation. It reaches the annual maximum in July, with an annual average of $174.9 \mathrm{~mm}$, and gradually decreases after September. It is the annual minimum in December, with an annual average of $2.0 \mathrm{~mm}$, There are significant differences in seasonal precipitation [26], which is generally consistent with the seasonal climate characteristics of rainy summer and dry winter.

By further analyzing the seasonal variation characteristics of long-term series precipitation in Tongzhou District in recent 65 years $(0)$. The results show that the increasing trend of spring precipitation is significant, the increasing rate is $0.35 \mathrm{~mm} \mathrm{a}^{-1}$, and the interannual variation is large. Among them, the spring precipitation in 1990 is the largest, $145.9 \mathrm{~mm}$; The summer precipitation showed a decreasing trend as a whole, and fluctuated and increased after 2000, but the summer precipitation contributed the most to the annual precipitation; The autumn precipitation showed an increasing trend as a whole, and the precipitation changed greatly in the 1980s; The precipitation in winter shows a decreasing trend, with the maximum precipitation of $30.3 \mathrm{~mm}$ and the minimum precipitation of $0.4 \mathrm{~mm}$, with a difference of $98.7 \%$. 


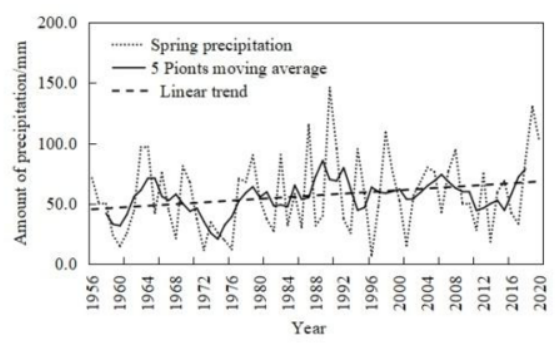

(a)

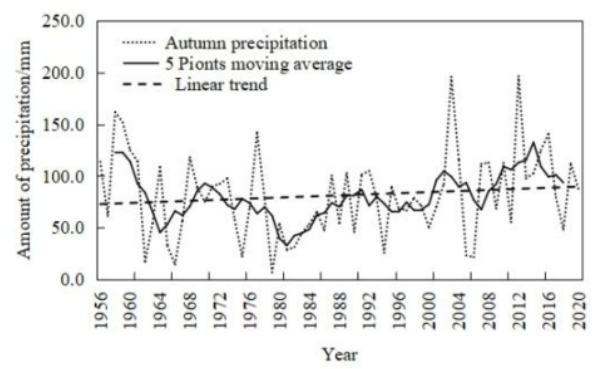

(c)

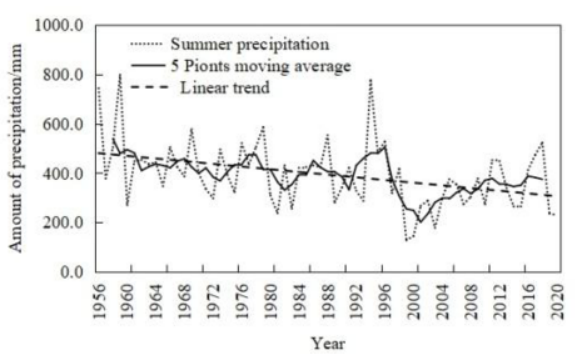

(b)

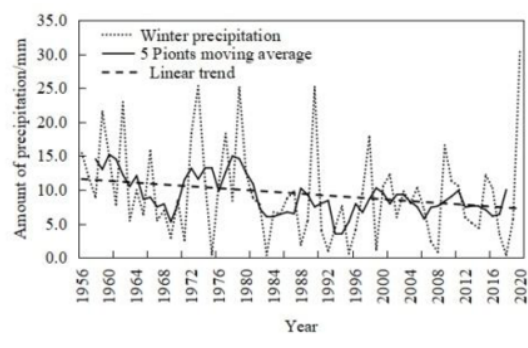

(d)

Figure 6. Variation of seasonal precipitation.(a) spring; (b) summer; (c) autumn; (d) winter.

\subsection{Precipitation Cycle Analysis and Future Trend Prediction}

The precipitation period analysis is carried out by spectral analysis method. The peak value in the curve is the main period [27], as shown in figure 7. The results show that there are three peaks in the spectral density map, corresponding to $4 \mathrm{a}, 7 \mathrm{a}$ and $15 \mathrm{~A}$ respectively. Therefore, there are obvious periodic oscillations of $3 \sim 5 \mathrm{a}, 6 \sim 8 \mathrm{a}$ and 14 $\sim 16 \mathrm{a}$ in the interannual scale of precipitation in Tongzhou area.

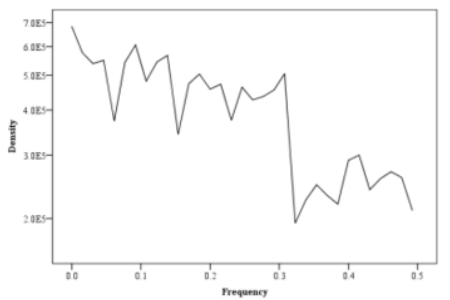

Figure 7. Precipitation spectral density map.

Combined with ARIMA model, the change trend of annual rainfall in Tongzhou District in the future is predicted, the precipitation data is smoothed, and the autocorrelation and partial autocorrelation analysis of the first-order difference of precipitation are carried out to meet the application conditions of the model. According to the historical precipitation observation data and future trend simulation prediction results, as shown in 0 , the simulation results basically reproduce the variation characteristics of precipitation, and the variation trends of precipitation simulation 
values and observation values are basically the same. According to the comparison results between simulated and measured precipitation values in 0 , the relative error between simulated and measured values is within $20 \%$. According to the prediction results of the model, the precipitation in Tongzhou District shows an increasing trend from 2021 to 2025, which basically conforms to the characteristics of periodic oscillation and the overall fluctuation trend of "decrease increase decrease increase decrease increase decrease increase".

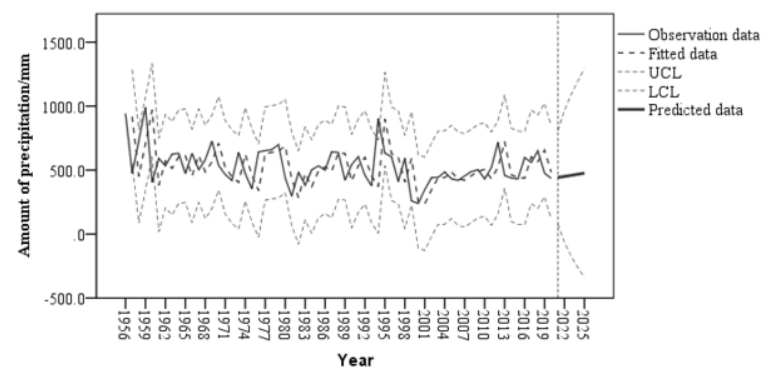

Figure 8. History and future trend of precipitation.

Table 2. Statistics of simulated and actual values.

\begin{tabular}{llll}
\hline Year & Observation data & Predicted data & Relative error/\% \\
\hline 2006 & 419.9 & 421.6 & 0.4 \\
2007 & 455.0 & 502.0 & 9.4 \\
2008 & 489.2 & 442.5 & 9.5 \\
2009 & 503.4 & 450.2 & 10.5 \\
2010 & 430.8 & 477.2 & 9.7 \\
\hline
\end{tabular}

\section{Results and Discussion}

Based on cumulative anomaly method, 5A moving average method, spectral analysis method and time series model, this paper analyzes the evolution characteristics and trend of precipitation in Tongzhou District. The analysis results show that:

(1) The annual average precipitation in Tongzhou District from 1956 to 2020, 1980 to 2020 and 2001 to 2020 shows the spatial distribution characteristics of high in the middle and northwest and low in the southwest. After 1999, it entered an obvious dry and rainy period. Along the Songzhuang, Gantang and Xiji lines in the middle of the region, the multi-year average precipitation of the sequence from 2001 to 2020 decreased by about $60 \mathrm{~mm}$ compared with the sequence from 1956 to 2020 .

(2) The average annual precipitation in Tongzhou District is $532.1 \mathrm{~mm}$, showing a fluctuating trend of "decrease increase decrease increase decrease increase decrease increase decrease increase" as a whole, decreasing at a rate of $2.42 \mathrm{~mm} \mathrm{a}^{-1}$. At the same time, the abrupt changes in the maximum and minimum precipitation occurred in 1959 and 2000 , with a ratio of 4.14 . The seasonal variation of precipitation is obvious. The precipitation in spring and autumn shows an increasing trend, while it shows an obvious downward trend in summer and winter. As the summer precipitation is mainly concentrated from June to August, accounting for $72.2 \%$ of the annual precipitation, the 
decrease of summer precipitation is the main reason for the decrease of annual precipitation.

(3) There are obvious oscillation periods of 3 8a and 14 16a in precipitation on the interannual scale. At the same time, ARIMA model predicts that the precipitation in Tongzhou District will increase from 2021 to 2025. However, due to many factors affecting regional rainfall, the time series analysis method is only used as trend prediction, and multiple factors need to be considered to establish a rainfall prediction model suitable for the plain area of Beijing, so as to make the rainfall prediction more reliable.

\section{Acknowledgements}

Thank my thesis instructor, Miss Zhang Juan. Without her tireless guidance and help and selfless modification of my thesis, I would not have finished this thesis. I would also like to thank Miss Guo Lin for her guidance and help. Here, I would like to express my heartfelt thanks to all the teachers who have guided and helped me!

This paper is supported by National Natural Science Foundation of China: hydrological change and ecological effect project of reclaimed water restoration in northern China (No: 4173000223)

\section{References}

[1] Ren GY, Jun YJ, Ren YY, Chen Y, Wang T, Liu YJ, Sun XB. The temporal and spatial variation of precipitation in Chinese Mainland -- I. climatological characteristics. Advances in Water Science. 2015 May; 26(03): 299-310.

[2] Liu XP, Tong XH, Jia QY, Xin ZH, Yang JR. Analysis on characteristics of precipitation concentration in China from 1960 to 2017. Advances in Water Science. 2021 Jan; 32(01): 10-19.

[3] Kong F, Fang JY, Liu F, Fang J, Shi PJ. Temporal and spatial pattern of precipitation concentration and concentration period in China from 1951 to 2012. Journal of Beijing Normal University (Natural Science). 2015 Aug; 51(04): 404-11.

[4] Duan YW, Zhu KY, Ma ZG, Yang Q. Variation and monthly distribution characteristics of precipitation concentration index (PCI) in China from 1961 to 2010. Chinese Journal of Atmospheric Sciences. 2014 Dec; 38(06): 1124-36.

[5] Zou XJ, Song XM, Liu CS, Zhang CH. Temporal and spatial evolution characteristics of precipitation in flood season in the Pearl River Delta. Water Resources and Hydropower Engineering. 2021 Jun; 52(06): 21-32.

[6] Lu J, Liu J, Liu MY, Cao YQ, Li LH, Ning Y. Multi scale analysis of precipitation in Beijing, Tianjin and Hebei in recent 55 years. Hydro-Science and Engineering. 2020 Dec; (06): 23-31.

[7] Liu L, Gao H, Zhang L, Wang Y L, Fu W. Decadal variation characteristics of precipitation in Wuhu area in recent 140 years. Research of Soil and Water Conservation. 2021 Sept; 28(05): 114-120.

[8] Li M, Xia J, Chen SM, Meng DJ. Wavelet analysis of precipitation change in Beijing in recent 300 years. Journal of Natural Resources. 2011 Jun; 26(06): 1001-11.

[9] Li B, Yu L, Pan XY, Ju Q, Zhang YH, Zhao LJ, Yang MY. Analysis of temporal and spatial characteristics of rainfall in Tongzhou District, Beijing. Journal of Beijing Normal University (Natural Science). 2020 Aug; 56(04): 566-72.

[10] Xia LB. Monthly precipitation trend forecast by spectral analysis. Meteorological Monthly. 1985 May; (05): 15-16.

[11] Chen P, Zheng WB, Liu WQ, Xiao M, Zhang LX. Analysis and prediction of some climate indicators in main crop producing areas of Yunnan Province Based on multiple models. Computer Science. 2020 Dec; 47(S2): 496-503.

[12] Zhao XW, Li YK, Zhang C, Zhang SH, Pan XY, Di SC. Flood risk analysis of Beijing urban area based on medium and long-term rainfall prediction. China Flood \& Drought Management. 2021 Jul; 31(07): 1-6. 
[13] Song XM, Zhang JY, Kong FZ, Wang GQ, He RM, Zhu K. Temporal and spatial evolution characteristics of extreme precipitation in Beijing. Advances in Water Science. 2017 Mar; 28(02): 16173.

[14] Pan XY, Xia J, Li FH, Liu HL, Ma M, Wang CZ, Li RX. Study on water resources carrying capacity of typical northern areas based on GIS -- Taking Tongzhou District of Beijing as an example. Journal of Natural Resources. 2007 Apr; (04): 664-71.

[15] Zuo BB, Xu ZX, Ren MF, Li P.. Study on precipitation characteristics in Tongzhou District of Beijing from 1966 to 2016. Journal of Beijing Normal University (Natural Science). 2019 Oct; 55(05): 556-63.

[16] Gao YN. Analysis of multi-year rainfall variation characteristics in Shenzhen. Soil and Water Conservation Science and Technology in Shanxi. 2021 Mar; (01): 4-6.

[17] Huang JY. Application of spectral analysis in meteorology. Meteorological Science and Technology. 1982 Jun; (03): 13-17.

[18] Ji C, Hou DW, Xie L, Sun H, Li FZ, Zhou Y, Deng AP, Shen HJ, Bao GJ, Wang YN. Health risk analysis and prediction of heavy metals in drinking water sources based on time series model. Environmental Science. 2021 May; p. 1-13. https://doi.org/10.13227/j.hjkx.202103122.

[19] Xue JM, Su LW, Yang K, Hu H. Analysis of temporal and spatial variation characteristics of precipitation in Luoyang. Water Resources and Power. 2016 Nov; 34(11): 13-16.

[20] An BJ, Zhou WB, Xia W, Yang H. Analysis on variation characteristics of Hydrometeorological elements in Fenghe River Basin. Journal of Water Resources and Architectural Engineering. 2019 Feb; 17(01): 239-43.

[21] Liu JX, Li DQ, Zhang HT, Liu N, Liu N. Analysis of precipitation trend in Xiaqu basin from 1956 to 2010. Journal of North China University of Water Resources and Electric Power(Natural Science Edition). 2015 Aug; 36(04): 12-14 + 19 .

[22] Li HX, Jie YW. Analysis of climate change characteristics in Ejina Banner. Journal of Gansu Agricultural University. 2013 Feb; 48(01): 112-117+ 124 .

[23] Wang JY, Wang SY, Yang HL, Zhu XL. Study on variation characteristics of rainfall and runoff in Shitou River Basin. Agricultural Research in the Arid Areas. 2011 Dec; 29(06): 179-83.

[24] Liu DL. ARIMA model prediction of annual precipitation in Zhengzhou. Research of Soil and Water Conservation. 2011 Nov; 18(06): 249-51.

[25] Chen ZF, Shi DM, He W, Xia JR, Jin HF, Lou YB. Study on temporal and spatial distribution and evolution trend of Rainfall Erosivity in Yunnan Province. Transactions of the Chinese Society for Agricultural Machinery. 2017 Oct; 48(10): 209-19.

[26] Huang JP, Zhang GL, Yu HP, Wang SS, Guan XD, Ren Y. Temporal and spatial characteristics of climate change in the Yellow River Basin in recent 40 years. Journal of Hydraulic Engineering. 2020 Sept; 51(09): 1048-58.

[27] Zhu ZY, Chen GY, Pan YY, Zhang J, Wang YA. Analysis of climatic characteristics and Service Countermeasures of area rainfall in Jinshuitan basin in recent 66A. Journal of Zhejiang Meteorology. 2019 Jun; 40(02): 18-24. 